\title{
VORBEMERKUNG ZUM TEXTTEIL
}

Eln * vor dem Namen einer Bibliothek bedeutet, daB der folgende $A b$ schnitt nicht auf Grund von Angaben verfaBt wurde, dle durch die betreffende Bibliothek geliefert wurden, sondern mangels solcher auf Grund von Mitteilungen zuverlässiger Drittpersonen oder von elnschlägiger Literatur.

Bestandes- und Zuwachsziffern, die ohne weiteres als runde Zahlen kenntlich sind, wurden ohne die Bezelchnung "rd" gelassen. Bestandesangaben in besetzten Brettmetern wurden nach der Formel: 1 Brettmeter $=30$ Bände (bei Volksbibliotheken $=40$ Bände) umgerechnet.

Die Offnungszeiten der Amts-, Anstalts- und Instltutsblbliotheken werden nur dann angegeben, wenn sle von den in der Sclıweiz ablichen Amtsstunden: 8-12, 14-18 Uhr, erheblich abwelchen.

Der Interurbane Leihverkehr zwischen den größeren und mittleren offentlichen Bibliotheken ist gut ausgebaut, auch an ausländische Bibliotheken werden Bücher und Handschriften, natürlich unter den allgemein üblichen VorsichtsmaBregeln, ausgeliehen, sofern Gegenrecht gehalten wird. Es wird darüber bei den elnzelnen Blbliotheken nichts welteres bemerkt. Amts-, Anstalts-, Instituts-, Seminar- und Klosterblbliotheken lelhen in der Regel nicht aus; sle sind auch für AuBenstehende nicht ohne weiteres zugänglich, doch werden ihre Vorsteher die Benutzung an Ort und Stelle den ernsthaften und gehörig legitimierten Interessenten in den meisten Fällen gestatten. Dle Kapuzinerklöster sind nach den Ordenssatzungen strenge angewiesen, Werke nur in seltenen Ausnahmen und stets nur mit besonderer Bewlliligung des zustăndigen $P$. Guardians auszuleihen, woraut wir aut Wunsch des Hochw. P. Provinzlals aufmerksam machen.

Bel doppelsprachigen Städten wurde die vorherrschende Form vorangestellt, bei einigen Städten des französischen Sprachgebietes die deutsche Form (Genf, Pruntrut) beigefügt. Die Einwohnerzahlen sind diejenigen der schweizerischen Volkszählung vom 1. Dezember 1930.

\section{ABKORZUNGEN}

\begin{tabular}{|c|c|c|c|}
\hline $\begin{array}{l}\text { Abt. } \\
\text { allg. } \\
\text { Ausg. } \\
\text { bes. } \\
\text { Bibl. } \\
\text { Cant., can } \\
\text { Dl. } \\
\text { Dlss. } \\
\text { Do. } \\
\text { eldg. } \\
\text { Fr. } \\
\text { gedr. } \\
\text { Hs., Hss. } \\
\text { Ink. } \\
\text { Kant., kan }\end{array}$ & $\begin{array}{l}\text { = Abtellung } \\
\text { = allgememin } \\
\text { = Ausgabe } \\
\text { = besonders } \\
\text { = Blbllothek(en) } \\
\text { = Canton(e), canto- } \\
\text { nal(e) } \\
\text { = Dlenstag } \\
\text { = Dissertation } \\
\text { = Donnerstag } \\
\text { = eidgenössisch } \\
\text { = Freitag } \\
\text { = gedruckt } \\
\text { = Handschrift(en) } \\
\text { = Inkunabel } \\
\text { = Kanton, kantonal }\end{array}$ & $\begin{array}{l}\text { Kat. } \\
\text { k1. } \\
\text { Mi. } \\
\text { Mo. } \\
\text { Nachtr. } \\
\text { Sa. } \\
\text { Schr. } \\
\text { So. } \\
\text { Suppl. } \\
\text { U. } \\
\text { UB. } \\
\text { Unlv. } \\
\text { vorges. } \\
\text { wlss. }\end{array}$ & 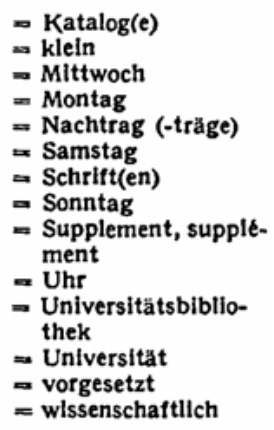 \\
\hline
\end{tabular}

Dle Auflösung der uabrigen Abkürzungen ergibt sich von selbst. 